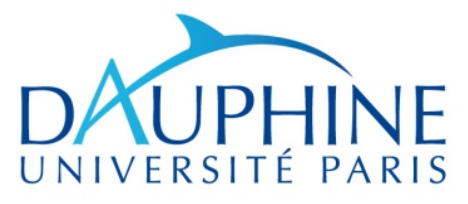

Laboratoire d'Analyses et Modélisation de Systèmes pour l'Aide à la Décision UMR 7243

\section{CAHIER DU LAMSADE 344}

Ocobre 2013

Protection of transport infrastructures against major accidents in and use planning policies. A decision support approach

Ch. Mazri, G. Lucertini, A. Olivotto, G. Prod'homme, A. Tsoukias

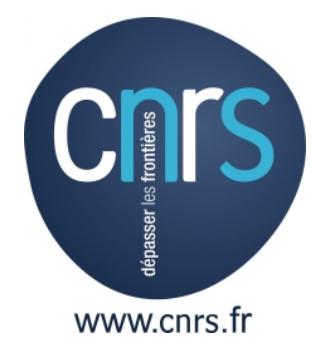




\title{
Protection of transport infrastructures against major accidents in land use planning policies. A decision
} support approach.

\author{
Ch. Mazri(*), G. Lucertini( $($ ), A. Olivotto(+), G.Prod'homme (*), A. Tsoukiàs(†). \\ (*)INERIS, Accident risks division, Parc Technologique Alata BP2, F-60550 Verneuil-en-Halatte, France. \\ (†)LAMSADE-CNRS, Université Paris Dauphine. Place du Maréchal de Lattre de Tassigny, France \\ (+)Università IUAV di Venezia, Santa Croce, 191, Venezia, Italy.
}

\begin{abstract}
Users of transport infrastructures nearby hazardous plants may represent important populations potentially impacted by a major accident. Toulouse catastrophe in 2011 has been an illustrative example as it strongly impacted highway users. Therefore, transport infrastructure users (Roads and railways mainly) represent a population to be protected within a land use planning policy as it is the case for inhabitants.
\end{abstract}

Accordingly, this paper presents a decision support approach aiming to help local stakeholders identifying the most cost effective measures to protect transport infrastructures from major accidental consequences. The suggested approach takes in account both technical and participatory constraints with the aim of offering an equal chance to all involved stakeholders to understand the issues under discussion and formulate opinions and values.

After a description of the French regulatory context, the major technical difficulties related to transport infrastructures protection will be described before introducing the main technical choices adopted by the team. Finally, a decision support procedure is described and a real case study presented.

This work is strongly embedded in the French regulatory context. However, we believe the decision support structure as fully adaptable to other regulatory contexts.

Keywords: Land use planning, decision support, transport infrastructures protection.

\section{Introduction}

Land use planning has been a pillar of industrial risk management policies in Europe since the first Seveso directive 82/501/EC in 1982. All the following revisions and evolutions of this directive (Seveso II in 1996 and Seveso III in 2012) have confirmed this status (4). Very synthetically, European policy on land use planning around hazardous plants is strongly oriented towards the future by dealing with modifications of existing installations, sitting of new ones or new developments of land uses (Seveso directive, article 12). The reader may find in (Lenoble et al, 2010) and (Grooijer et al, 2010) a more extended description of this policy and its applications in various European countries.

However, the Toulouse (France) catastrophe in 2001 did put the spots on the need to consider also heritage of past policies where proximity between dense populations and industrial hazards was accepted (MEDDE, 2006). Risk acceptability being a social and dynamic construct (Short, 1984; Renn, 1998), it evolves through time: what has been accepted in the past may be rejected in the future, especially after a big catastrophe as it was the case in France (IRSN, 2012) or more recently in Fukushima (Prati and Zani, 2012).

Therefore, France decided to take a step further in risk prevention by adopting the 699-2003 Act on technological and natural risks prevention. Regarding the industrial risks part of the law, regulators insisted on the need to define, around some hazardous plants ${ }^{1}$, land use planning processes that integrate safety criteria in future projects acceptation, besides correcting existing situations where cohabitation of hazards and vulnerable stakes is no more acceptable. Practically, this may lead for instance to expropriate either the hazardous site or some of its neighbors, whether they are inhabitants or other economic activities (MEDDE, 2006).

\footnotetext{
${ }^{1}$ Plants classified by Seveso regulation as highly dangerous (Tier up) regarding the type and quantities of hazardous substances stocked or involved in the production processes.
} 
The local public decision processes aiming to achieve those objectives are the Plans de Prévention des Risques technologiques $^{2}$ (PPRT). With respect to national acceptance criteria and technical directives, those participative processes provide local stakeholders with the opportunity of discussing the most adapted local equilibriums between safety on one hand and social and economic development on the other hand (Mazri, 2010). There are about 420 distinct PPRT processes planned for the whole France.

One of the key issues raised by those decision processes is how to deal with existing and future transport infrastructures (roads, railways) located in risky areas. Protecting transport infrastructure users is a complex problem for mainly two reasons. The first one is the linear character of those infrastructures making it possible for the same risk scenario to generate various consequences levels for different linear segments depending on their respective distances with the accidental source. The second is the usual large set of social and economic stakes usually associated to decisions on transport infrastructures (Lakshmanan, 2011).

This paper will present an original and pragmatic approach aiming to support decision making on transport infrastructures protection given the PPRT context. In the next sections, we will be equally interested in describing the technical related issues we have been dealing with and the policy making related ones that present, in our opinion, interesting insights to the community of decision support providers in public risky contexts.

\section{The PPRT Framework}

As specified earlier, PPRT are public decision processes aiming to both correct existing unacceptable territorial configurations and shape future territorial evolutions regarding industrial risks. It would go far beyond the objectives of the present paper to provide the reader with a full description of the specificities and evolutions introduced by the PPRT in the French regulation on land use planning. An extensive description is provided by Lenoble and Durand (2011) and Taveau (2010). We will thus focus on salient elements regarding the issue of transport infrastructure protections. We will proceed to the presentation of the PPRT framework according to its technical, organizational and financial features.

\subsection{Technical features of PPRT}

Risk is usually understood as a combination of a probability and the scope of consequences (Duijm, 2009) despite the various meanings the concept of probability may carry (Aven, 2013). Accordingly, Risk can be defined through the following formula:

$$
R i s k=P \otimes C=P \otimes I \otimes V
$$

$\boldsymbol{P}$ : Probability associated to a given accidental scenario.

$\boldsymbol{C}$ : Severity of consequences regarding the stakes under consideration (human, ecological, material...).

$\boldsymbol{I}$ : Intensity of one or several effects generated by the scenario. For instance: Heat flows in case of thermic effects, Toxic concentrations in case of toxic releases...

$V$ : Vulnerability of stakes under consideration regarding the intensity level.

In the PPRT framework, risk is defined in a slightly different way according to the following formula:

$$
R i s k=P \otimes I \otimes K \otimes V=A \otimes V
$$

$A$ : Stands for 'Aléa' and defines the probability that a dangerous phenomenon creates effects of a given intensity and over a determined time period at a given point of the territory (MEDDE, 2006). In addition to the classic probability criterion, Aléa are characterized according to the two following additional criteria:

- I : A description of the various potential effects (overpressure, toxic, continuous or transient thermic) and the modeling of their respective intensity propagation. For instance, a Boil over will generate both overpressure and transient thermic effects for which different modeling will be performed.

The variations of intensity levels for each effect are set according to three thresholds:

- Very serious consequences threshold (LC 5\%) define zones within which at least 5\% lethality is expected regarding the intensity level.

- Serious consequences threshold (LC 1\%) defines zones where lethal effects may impact less than $1 \%$ of the population.

\footnotetext{
${ }^{2}$ Technological Risk Prevention Plans.
} 
- Significant consequences threshold ( $L C$ O\%) defines zones where no lethality is expected but still irreversible injuries are likely to happen.

Depending on the number of people impacted in each zone, a qualitative assessment of consequences seriousness is performed according to the matrix detailed in table 1 below.

\begin{tabular}{cccc}
\hline & $\begin{array}{c}\text { Very serious } \\
\text { consequences }\end{array}$ & $\begin{array}{c}\text { Serious } \\
\text { consequences }\end{array}$ & $\begin{array}{c}\text { Significant } \\
\text { consequences }\end{array}$ \\
\hline Disastrous & $>10$ & $>100$ & $>1000$ \\
Catastrophic & $1-10$ & $10-100$ & $100-1000$ \\
Important & $<1$ & $1-10$ & $10-100$ \\
Serious & 0 & $<1$ & $1-10$ \\
Moderate & 0 & 0 & $<1$ \\
\hline
\end{tabular}

Table 1 Seriousness scale of consequences according to French regulation (MEDDE, 2006).

- $\quad \boldsymbol{K}$ : An appreciation of the time duration required for each effect to reach vulnerable stakes starting from its detection. This kinetic criterion aims at assessing the opportunity to deal with a given scenario through an emergency planning procedure (if the kinetic is slow) instead of a land use planning one (in case of fast kinetic).

Those scenarios are aggregated in order to elaborate individual risk maps dividing the territory into concentric Aléa zones ranging from very high to very low (see figure 1 for an example). Once such zones are established the planning proceeds as follows.

Figure 1 Example of an Aléa map.

a. Within the risky areas identified in the previous step, an inventory of stakes is elaborated. The term stakes is here only focused on human safety and no consideration is given to material or ecological damages. Schools, habitations, economic activities or transport infrastructures are examples of stakes considered in the PPRT because of their human frequentation.

b. Aléas and stakes maps are superimposed and when necessary, vulnerability assessments are conducted to evaluate the ability of some constructions to protect their users regarding the Aléas level impacting them.

c. Depending on the variety of Aléas and vulnerability combinations, the following decision alternative are made available:

- Aléas reduction through adapted technical or organizational measures aiming to reduce either the probability or the intensity associated to one or several accidental scenarios.

- Mandatory expropriation and compensation of the plant generating the risk or of one or several of its neighbors impacted by unacceptable risk levels.

- $\quad$ Relinquishment and compensation of inhabitants.

- Preemption offering local authorities the priority in purchasing habitations to be sold within risky areas. On the long term, this should gradually reduce inhabitants' concentrations in risky areas.

- Constructions reinforcement in order to reduce vulnerability to Aléas.

\section{2- Organizational features of PPRT}

To conduct those steps, local decision processes are set up according to the following national orientations:

- The final decision maker is the one in charge of conducting the PPRT process and coincides with the local representative of the government, namely the 'Préfet'.

- If the decision power is not shared with other local stakeholders, participation is, however, imposed by regulation ${ }^{3}$. More precisely, a minimal set of participants is to be systematically involved (industrial operators, different levels of local authorities from mayors to regional authorities, representatives of workers and of lay public) with the possibility for the Préfet to include any additional stakeholder believed as relevant. Furthermore, minimal organizational arrangements are also imposed: participation terms need to be discussed with participants, their respective opinions and remarks are to be discussed at each technical step, at least one public hearing is to be conducted at the end of the process...

- Depending on the combinations of Aléas and vulnerabilities, some of the decision alternatives detailed above are mandatory whereas other optional. Under the supervision of the Préfet, it is the responsibility of local stakeholders to define the most context-adapted combination of mandatory and optional alternatives to ensure both territorial development and people's safety.

\footnotetext{
${ }^{3}$ Article L515-22 of French Environmental regulation.
} 


\section{3- Financial features of PPRT}

Land use planning around hazardous sites is a public issue since it implies the use of public resources (Ostanello and Tsoukias, 1993). However, in the case of PPRT, it is more relevant to talk about a repartition of public and private resources to finance the final decisions to be taken which, by the way, can be highly costly as expropriation or buildings reinforcement.

Since the repartition of the financial burden between public and private actors shapes their respective positions and expectations in terms of decision support, it is important to understand how the French regulation defined the terms of costs allocation among stakeholders.

- When expropriation is required (both mandatory and voluntary), financing is shared between public and private resources. Public resources come both from the government and the local authorities whereas private resources are provided by the industrial operator generating the hazard.

- Preemption is exclusively chargeable to local authorities.

- Buildings reinforcement is funded differently depending on the owner. In case of private houses, costs are shared between inhabitants and government. However, if the buildings are owned by local authorities (schools, city halls...) or economic operators (industrial plants, shops...) all the costs are at their charge.

- In case of Aléas reduction, costs are chargeable to the industrial operator.

It is worth noticing that the terms of repartition described here reflects two main policy orientations adopted at a national level:

- Only habitants of risky areas receive financial support from the government to correct inherited risky situations. Public (local authorities) and private (economic activities and transport infrastructures) are excluded.

- The risk is defined as a societal issue requiring financial contributions from all stakeholders obtaining some benefit from some risk generating activity: industrial operators being the source and the first beneficiary of the risky activity, government and local authorities as beneficiaries of national and local taxes, inhabitants and local economic activities as beneficiaries of secondary economic impacts as employment opportunities.

Given the PPRT features detailed above, the next section is intended to focus on the description of the infrastructure protection problem within the PPRT context.

\section{Transport infrastructures protection: the problem}

The term transport infrastructure encompasses both linear segments (roads, railways) and punctual ones (train stations, toll booths...) necessary to ensure transportation services. Accordingly, those types of stakes present some specificities that influence the decision making process, and consequently, the type of decision support required.

\section{Combinatorial explosion of Aléas}

The difficulty when dealing with linear segments is that, in addition to the potential variety of effects that may impact them (thermal, toxic, overpressure), each impact may generate simultaneously different consequence levels for different linear segments depending on their respective distances with the accidental source.

Consequently, characterizing linear segments regarding the type and level of aléas raises very quickly combinatorial issues. A real case example is provided in figure 2 below.

Let's consider an $800 \mathrm{~m}$ long railway segment in the vicinity of a hazardous site for which the following accidental phenomena have been identified and characterized:

- Boil over generating both overpressure and transient thermic effect;

- Flash fire producing transient thermic effects;

- Hydrocarbons combustion leading to continuous thermic effects.

The gradient of intensity generated by each of those phenomena leads to distinguish areas depending on the hazard level they are submitted to. As hazard is defined by likelihood, intensity and kinetic, we have identified almost 20 distinct segments for which various levels of aléas apply.

This example shows the increased complexity related to linear stakes comparatively to punctual ones when it comes to assess their exposure to hazards.

Figure 2 Combinatorial aspect in characterizing hazard exposure of linear stakes. 


\section{Variable vulnerabilities}

In addition to the hazard related complexity described above, vulnerability related complexity is also to be emphasized regarding particularly the variability in infrastructures frequentation. Basically, a same infrastructure may, depending on daily or even yearly periodicity, experience different levels of frequentation. For instance, working hours or school opening periods can dramatically increase some infrastructures frequentation and even reach saturation thresholds. This last case may dramatically change the vulnerability configuration of users from a timely exposure to a given effect to a permanent one.

\section{$\underline{\text { Value systems }}$}

Several value systems had to be considered during the decision support process. The first pattern of values was almost at the origin of the increased interest given to transportation infrastructure. Basically, as government was pushing local stakeholders to invest private resources in reinforcing buildings, those in return asked government and private operators to invest more in protecting users of transportation infrastructures. It is thus worth to note that claims of fairness in public and private resources investments were the first motivations of putting on the top of the pile the issue of transportation infrastructures. This confirms a large set of literature findings on the importance of fairness in risk perception mechanisms (Webler and Renn, 1995) (Okrent, 1998)

The second pattern of value systems goes beyond the PPRT and is related to the French industrial risk management policy in general which does not acknowledge cost benefit analysis as a framework for decision making. The value system underneath this position is a reluctance to rely on financial valuing of human life when it comes to answer the 'How safe is safe enough?'

These two patterns of values have strongly oriented our methodological choices to be presented later on this paper.

\section{Final users}

The decision support approach is meant for local stakeholders in charge of building a common understanding of the protective measures to be taken regarding transport infrastructures. The profile of such users is however extremely variable, ranging from technical engineers usually in charge of risk assessment to perfect profanes with a very low technical background.

Within such participative contexts, decision support tools are hopefully less complex (Rosenhead and Mingers, 2004) in order to ensure that participants, whatever their technical background, understand the successive implications of technical choices and the values underneath them. Consequently, we considered the need to keep our methodological approach as simple as possible, this being an important requirement to improve transparency and participation.

Considered all together, these specificities allow us now to suggest a problem formulation related to infrastructure protection within the PPRT framework.

Given a transport infrastructure impacted by industrial hazards and object of a PPRT process, a decision support approach is required by a set of local stakeholders to help building a collective and shared argument on the most adapted protective measures to implement within a limited budget.

\section{Decision support methodology}

Before detailing the operational steps of the suggested methodology, it is worth presenting the major methodological choices made by the team and the rationalities lying behind them.

\section{1- Main hypotheses}

\section{Aléa modeling}

In order to deal with the combinatorial explosion resulting from the combination of various levels of likelihood, intensity and kinetic, we decided to avoid characterizing exposure through the exact definition of aléas levels affected to each linear segment. Instead, we consider sufficient (for our purpose) to maintain aléas description based on a list of scenarios described according to the three criteria being probability, intensity and Kinetics.

In that way, we will deal with a set of risk scenarios for which protective measures are to be defined instead of dealing with a set of linear segments differentiated according to aléas levels impacting them. Such an orientation can be justified for the following two main reasons:

- The list of scenarios and related performances on the three criteria (probability, intensity and kinetic) is already an available information and no additional processing is required. It is thus a significant saving in resources consumption comparatively to the need of characterizing linear segments. 
- By dealing with each scenario individually, PPRT participants are more willing to understand the issues discussed and actively participate in selecting most adapted measures according not only to safety criteria but also to economic or practical ones.

\section{An averaged estimation of consequences severity}

As stated previously, depending on frequentation periodicity of transport infrastructures, the number of people exposed, and consequently, the severity of consequences may highly vary depending on time occurrence of the accident. In order to handle this variability in a rigorous and still understandable manner, we suggest firstly adopting an index of infrastructure frequentation representing an evaluation of population exposed to a given risk scenario. Of course, this index will have to explicitly acknowledge frequentation variability over time.

Secondly, according to this representation of the number of people exposed, a severity scale will be defined in a very similar way than for punctual stakes as described in table 1 earlier.

\section{Frequentation index (FI)}

For a given infrastructure transport experiencing $\mathrm{K}$ different levels of frequentation during a time period of reference $\mathrm{T}$, this index is calculated according to the following formula:

$$
\text { Frequentation index }=\sum_{i=1}^{K} \frac{f_{i}(t) * D * N}{S} * \frac{t_{i}}{T}
$$

$f_{i}(t)$ : Function describing for each time period $i$ the vehicles flow (cars, trains...) characterizing the infrastructure frequentation.

$D:$ The length of the linear segment impacted by the scenario.

$N$ : Average number of persons per vehicle.

$S:$ Vehicles average speed.

$t_{i}$ : Duration of the time period $i$.

$T:$ Reference time period.

Let's take the example of a road impacted by significant lethal thermic effects on a $0,3 \mathrm{Km}$ section. Two frequentation levels $(i=\{1,2\})$ are to be distinguished on a yearly basis. During holidays (2 months per year), frequentation jumps to 30000 vehicles per day $\left(f_{1}(t)\right)$ whereas it is limited to 20000 vehicles per day $\left(f_{2}(t)\right)$ during the rest of the year (10 months). Speed is limited to $80 \mathrm{Km} / \mathrm{h}$ and each vehicle carries 3 passengers. According to those inputs, the frequentation index is calculated as follows:

$$
\mathrm{FI}=\left(\frac{30000 * 0,3 * 3}{80 * 24} * \frac{2}{12}\right)+\left(\frac{20000 * 0,3 * 3}{80 * 24} * \frac{10}{12}\right)=10,15
$$

Values calculated by this index are purely artificial and do not represent any physical reality. However, they give a quantitative representation allowing comparison either between different infrastructures or between different states of the same infrastructure before and after selecting one protection alternative. It is thus meant for comparison and benchmarking and not for absolute evaluation.

This frequentation index is to be calculated also for the other consequences levels described earlier, being first lethal effects and irreversible injuries.

\section{$\underline{\text { Severity of consequences }}$}

Now that variability of frequentation has been taken into account through an index, it is possible to evaluate the severity of consequences in the same manner that it is done for punctual stakes (see table 1). Table 2 below shows an example ${ }^{4}$ using the frequentation index suggested above in order to evaluate the severity of consequences for transport infrastructures. For the sake of clarity and homogeneity, we choose to adopt the same qualitative scale than the one adopted in table 1 which ranges from moderate to disastrous.

We will rely on this suggestion in the forthcoming sections in order to demonstrate the applicability of the suggested approach.

Table 2 Example of severity calculations based on the frequentation index.

\footnotetext{
${ }^{4}$ This proposal has no legal value and does not substitute to any ongoing regulation.
} 


\section{Decision alternatives}

After several meetings with technical experts in infrastructures protection, we developed a typology of decision alternatives aiming to reduce either scenarios likelihood and intensity or infrastructures vulnerability.

- Type 1: Technical and organizational measures allowing reduction of accident complications

If the effects of an accident reach the infrastructure users, it is realistic to consider that the traffic will be altered inducing further possible traffic accidents referred to in the following as accident complications. Therefore, this first category of alternatives is meant for all intensity levels where users may lose control of their vehicle and generate lethality or injuries not directly related to the aléa consequences.

Accordingly, the following options are suggested:

- Appropriate signaling positioned upstream to alert users entering the infrastructure segments exposed to the accidental consequences.

- Reinforced carriageways separation reducing the possibility of perturbations impacting other carriageways.

\section{- Type 2: Organizational measures aiming to reduce infrastructure frequentation}

Risk is here treated through organizational dispositions aiming to reduce infrastructure frequentation, either permanently or only in case of accident occurrence. Actually, we distinguish within this second category the following alternatives:

- Permanent reduction of infrastructure frequentation through reconfiguration of traffic flows. This reconfiguration can be total (only industrial uses are allowed so to provide logistics within the hazardous sites) or partial (allowing all type of users, but still incentivizing to report traffic on alternative transportation infrastructures). The incentives we are talking about here can be either financial (increasing toll fees) or informational by modifying upstream signaling system so to orient users towards other pathways.

- If the scenario kinetic allows it, study the possibility of an alert system which, combined with barriers placed upstream the hazardous plant, stops or at least grandly reduces traffic flows before the dangerous phenomenon reaches the transportation infrastructure. However, implementing such an alternative requires a well calibrated and regularly trained organization allowing a fast and reliable reactivity in case of alert.

- The third and last option is to be studied when risk scenarios are related to punctual, but highly dangerous activities. For example, truck unloading activities may generate $\mathrm{UVCE}^{5}$ with potentially high consequences, especially when unloading areas are close to the plant limits. These punctual and still highly dangerous operations can be scheduled in time slots which avoid periods of high traffic or saturation, thus reducing the gravity of potential consequences.

\section{- Type 3: Hazard reduction measures}

Depending on the plant specificities and the risk scenarios identified, various possibilities to reduce hazard potential and associated probabilities can be studied. For the sake of example, the following possibilities might be considered:

- Reduce pipes diameters if associated risk scenarios impact the infrastructure.

- Displace unloading areas far from the infrastructure with the condition of not increasing the risk for other human stakes.

- Type 4: Physical measures of vulnerability reduction

Vulnerability reduction is here achieved through constructive measures adapted to the type and intensity of adverse effects. Three types of protections might be studied:

- One side constructions: Bunds or walls may offer adapted protection against continuous thermic effects and weak overpressure levels (INERIS and CETE, 2012). However, they are totally unfitted in case of toxic release or cloud inflammation.

Figure 3 One face protection.

- Two sides constructions: Those structures combine a wall and a partial or total roof with the aim of a better protection (comparatively to one sided constructions) against overpressure and continuous thermic effects. However, this improvement in protection performance increases costs and does not provide satisfactory answers against toxic effects (INERIS and CETE, 2012).

\footnotetext{
${ }^{5}$ Unconfined Vapor Cloud Explosion
} 
Figure 4 Two faces construction.

- Three sides constructions (tunnels): Through a complete covering of the transportation infrastructure, it is potentially possible to achieve a full protection of users against all effects types and intensities. However, costs are particularly high $^{6}$ especially in case of toxic effects requiring adapted ventilation systems.

Figure 5 Protection tunnel

The various decision alternatives described here aim at providing decision makers with a wide range of options to be discussed according to their relevance given the local context and their performances in terms of safety and feasibility (costs, infrastructure disturbances during construction phases...). Each of those alternatives offers specific advantages and limits making it interesting for local stakeholders to seek for an adapted combination of options instead of selecting the best one.

The aim of the decision support approach suggested in the following section is to help the local set of stakeholders in exploring the set of local risk specificities and the space of options to find the most adapted combination of answers.

\section{2- The decision support procedure}

Step 1: Risk scenarios classification

At this stage we consider all the accidental scenarios that may occur within the plant under analysis. According to Aléa maps (as described in figure 1), scenarios with very low or no impacts on the infrastructure are removed from the procedure.

The remaining risk scenarios are then listed and characterized according to the following criteria:

- Probability of occurrence.

- Frequentation index (FI) associated to each of the three aléa levels (very serious, serious and significant). As described earlier, this index aims at describing levels and types of exposure potentially faced by the infrastructure users.

- Associated kinetic measured by the duration of the accidental sequence from its detection to the impact on infrastructure users.

Table 3 Suggested properties to characteriz risk scenarios.

According to these properties, scenarios are sorted out using an acceptability matrix as described in figure 6 below.

Table 4 Example of an acceptability matrix for infrastructures protection.

The color code used in this matrix is the following:

- Green zone describes extremely low levels of consequences with no fatalities and very low levels of irreversible injuries. All scenarios affected to this zone could be considered as acceptable and thus be excluded from the analysis.

- The blue zone regroups scenarios with serious consequences (no fatalities but possibly important irreversible injuries) and important consequences (possible fatalities) with a very low level of probabilities (below $10^{-5}$ ). Because of the injuries that may affect the abilities of drivers to control their vehicles, we are particularly interested here in limiting accidents complications. Therefore, all scenarios affected to this category are to be treated through type 1 alternatives (reduction of accidents complications).

- The orange zone defines a tolerability area (HSE, 2001) for which efforts should be deployed with respect to economic feasibility.

\footnotetext{
${ }^{6}$ Ranging from 25000 to $300000 €$ per meter depending on construction specificities (INERIS and CETE,
} 2012). 
- Risk scenarios affected to the red zone are of high consequences to infrastructure users and should be thus considered as unacceptable.

Before going more in depth in identifying risk treatment measures, some additional remarks are to be considered here:

- This matrix has no regulatory value and is suggested exclusively for the sake of example. It is the responsibility of public decision makers to define acceptability thresholds and the resulting acceptability matrix. Our aim here is limited to suggest the use of a probability/severity matrix as a decision support tool to classify risk scenarios.

- The probability and consequences scales used in figure 6 fit the French regulation. However, other scales can be used as long as the meanings of the various acceptability areas suggested are preserved.

- Depending on the values taken on the three FI criteria (Yi, Zi, Ti), one scenario can be affected simultaneously to several cases of the acceptability matrix. For example, let's consider a risk scenario S1 with the performances described in table 4 .

\section{Table 5 Scenario Example}

Given the probability level (Qualitative category C), $\mathrm{S}_{1}$ severity is to be characterized simultaneously as:

- important regarding very serious consequences,

- catastrophic regarding serious consequences,

- Disastrous regarding significant consequences.

Accordingly, this scenario will occupy simultaneously three distinct cases in the acceptability matrix.

Step 2: Exploring risk treatment measures for scenarios in red and orange zones

As stated previously, our procedure aims at identifying not only one alternative but a combination of alternatives offering the most adapted solution for a given context. The term "adapted" is here considered under both technical and economic considerations. This last consideration is of particular importance if we remember that some alternatives, especially type 4 ones, can be extremely costly. Therefore, we will privilege combinations based on types 2 and 3 alternatives before appealing to vulnerability reduction measures.

The first step is thus dedicated to explore the following options without any preference or priority to one among the others.

\section{a. $\quad$ Studying evacuation possibilities}

Risk scenarios being characterized by their kinetic, we suggest studying the existence of technical and organizational arrangements aiming at evacuating infrastructure users within adapted delays. More precisely, evacuation can be performed through upstream physical barriers and signaling systems managed by an adapted organization.

An associated procedure is to be defined in order to evaluate a realistic duration to effectively stop traffic once accident is detected. If scenario kinetic is strictly higher that this duration, scenarios can be excluded from the analysis and no further reflection is required. However, it is important to acknowledge that in this case, safety of infrastructure users relies on organizational performances that need to be constantly maintained through adapted trainings and operational exercises.

\section{b. $\quad$ Avoiding dangerous activities during saturation or high traffic periods}

Some punctual activities, such as loading/unloading, may generate scenarios with large consequences even if those risks are limited in time. A practical option to explore would be the limitation of these activities to periods where infrastructure frequentation in reduced. This would be particularly adapted to infrastructures experiencing daily traffic variations allowing dangerous activities to be conducted during low frequentation periods.

The result will be that some consequences will be associated to low frequentation levels and the relative scenario will be displaced to lower severity cases.

However, it is important to make sure that those restrictions on logistic activities do not lead to increase dangerous products stocks which, in return, may increase other scenarios severity.

\section{c. Hazard reduction}

Another way to deal with critical scenarios is to study the possibility of reducing probability or severity through additional safety barriers, replacement of dangerous products in the production process, evolutions towards safer technologies or simply reduction of dangerous products quantities. For instance, internal pipeline diameter can be reduced and thus, lower loss of containment consequences. 


\section{d. Permanent reduction of infrastructure frequentation}

Limiting infrastructure frequentation to industrial purposes, avoiding the use of impacted segments by public transportations or report traffic to other infrastructures are options to be studied locally given the available possibilities and the economic and social stakes.

These various alternatives should be considered individually for each risk scenario in orange and red zones with the aim of displacing them to lower zones. At the end of this phase, the following acceptability rules are suggested:

- All scenarios still in red zones will be treated in phase 4 (see further on).

- All scenarios in orange zones are tolerable as the set of options described above did not allow an improvement in safety given a reasonable amount of economic resources.

Step 3: vulnerability reduction

This fourth type of alternatives is dedicated to risk scenarios that remain unacceptable (red zone) despite the study of alternatives of type 1,2 and 3.

The only available option at this level is the reduction of infrastructure vulnerability through "constructive measures" (constructing physical barriers).

Expert assessments need to be performed in order to study the feasibility of such options with respect to:

- Their protective performance regarding effects types and intensities.

- Feasibility regarding traffic perturbation and land availability.

- Construction and maintenance costs.

We suggest local stakeholders to seek for at least two types of constructive measures:

- Partial and still acceptable protection. Experts will be asked to propose the cheapest constructive alternatives allowing displacing all scenarios out of the unacceptable zone. This solution is to be considered as the lower bound of constructive measures.

- Total protection. Experts deliver here the upper bound of constructive measures that offer a complete protection to the infrastructure users regarding unacceptable scenarios.

- Complementary to those two categories of alternatives, experts can suggest (if possible) intermediate solutions that differ either in costs or efficiency within the bounds identified above.

We emphasize the importance of providing the local stakeholders with various options given the cost criteria. Dealing with a unique alternative providing total protection with extremely high cost, may rapidly lead the negotiations to a stalemate.

\section{Step 4: The global scenario(s)}

Steps 1, 2 and 3 have been dedicated to study partial solutions dealing individually with each risk scenario. From mitigation of accident complications to vulnerability reduction, various options have been studied separately. This final step aims at considering globally those various solutions in order to:

- Evaluate complementarities among the solutions studied individually.

- Eliminate potential redundancies.

- Assess the global performances of infrastructure protection options especially regarding efficiency and costs.

The difficulty in achieving these objectives lies in the fact that the various categories of options presented above may interact and consequently modify the individual efficiencies. More clearly, the efficiency of one option considered alone may be reduced when combined with another one. An easy illustrative example concerns the use of two sides protection: from a "vulnerability" point of view this will likely protect drivers against both lethal effects and irreversible injuries making it useless to mitigate accident complications through an additional dedicated measure.

Figure 7 below illustrates options interactions to be systematically considered within this phase. Represented as an oriented graph (Diestel, 2006), arcs describe a potential of efficiency reduction of the final vertex resulting from an interaction with the initial one. 
Figure 6 Options interactions regarding efficiency criterion.

- Arcs a, b and c describe situations where adopting types 2, 3 or 4 options may question the relevance of type 1 options if adopted earlier. This is due to the ability of types 2, 3 and 4 to avoid accident complications in addition to their first respective aims.

- Arcs d and e illustrate that types 2 and 3 options need to be studied simultaneously in phase 2 as hazard reduction for one scenario can make it useless to reduce infrastructure frequentation due to another scenario and reciprocally, reduction of infrastructure frequentation may make hazard reduction options redundant.

- Arcs $f$ and g illustrate how vulnerability reduction may cover all safety objectives fulfilled by type 2 and 3 options. Therefore, if stakeholders accept the possibility to implement a vulnerability reduction measure, it is necessary to reexamine the need of other options under this new perspective.

The short procedure described here aims at tackling exhaustively potential options interactions. However, our first experiments demonstrate that few interactions are to be considered for each case making it easy to deal with it cognitively without requiring the support of a procedure.

\section{Case study}

We present a case study to which our approach has been applied as a pilot. For confidentiality reasons the name and location of this experiment are not disclosed.

The transport infrastructure studied is a railway linking two urban centers with a traffic estimated at 2900 passengers daily.

The hazardous plant is located in a poorly dense area making the protection of railway users the main focus of this PPRT. Hazardous effects to be considered are mostly overpressure and thermic. A global vision of the risks impacting this infrastructure is presented by the aléa map in fig 8 below.

\section{Figure 7 Aléa Map}

The railway infrastructure is impacted on a $650 \mathrm{~m}$ long section. Statistical studies did not demonstrate any periodicity in traffic variations. Train speed in this section is $15 \mathrm{Km} / \mathrm{h}$ due to the proximity of a train station.

Step 1: Risk scenarios classification

Table 5 presents the list of scenarios identified by the safety report and their characterization according to the criteria presented previously in table 3 . Some scenarios are mentioned repeatedly because they relate to comparable installations in different areas of the plant.

For the sake of clarity, as far as the frequentation index calculation is concerned, we also detailed the sections lengths impacted by each consequences level (Very serious, serious and significant) of each scenario.

For example, scenario 14 impacts $370 \mathrm{~m}$ of the infrastructure with very serious consequences, $130 \mathrm{~m}$ with serious consequences and $120 \mathrm{~m}$ with significant consequences. Accordingly, the calculation of frequentation indexes is performed as follows:

$$
\begin{array}{ll}
- & \mathrm{FI}_{\text {Very Serious }}=\frac{2900 * 0,37}{15 * 24}=2,98 \\
- & \mathrm{FI}_{\text {Serious }}=\frac{2900 * 0,13}{15 * 24}=1,04 \\
- & \mathrm{FI}_{\text {Significant }}=\frac{2900 * 0,12}{15 * 24}=0,96
\end{array}
$$

Table 6 Frequentation index calculation for the various risk scenarios. 
The classification of scenarios in the acceptability matrix is detailed in figure 9.

Table 7 Scenario classification

Scenarios classification emphasized the following conclusions:

- The red zone remains empty which excludes the need to consider constructive measures to reduce vulnerability.

- Scenarios 6, 7, 9, 10, 11, 15 and 22 may generate accidents complications on the respective impacted segments.

The infrastructure we are talking about here being a railway, we are interested in ensuring that the train driver will be able to keep control of the vehicle even after being impacted by one of those scenarios.

Regarding the extremely low speed considered and the proximity of a train station, railway safety devices will allow stopping the train at the station if the driver is not in situation to perform it.

Accordingly, no further measures are suggested to deal with those effects levels.

- Scenarios 6, 7, 9, 11, 14, 15, 16 and 22 will require a more in depth analysis to assess the relevance and feasibility of either or both hazard reduction and infrastructure frequentation options.

Step 2: Exploring risk treatment measures for scenarios in red and orange zones

As stated earlier, we suggest studying firstly the possibility of evacuating the infrastructure before the hazardous effects impact it. Existing emergency plans demonstrate that 2 hours are today necessary for a complete evacuation of the infrastructure. However, more sophisticated alert and detection devices coupled with an adapted organization may reduce the duration to less than one hour.

The effective implementation of an improved emergency planning will thus allow to completely protecting infrastructure users against scenarios $11,15,16,18$ and 20.

At this point, the transport infrastructure remains vulnerable to scenarios 6, 7, 9, 11 and 22 .

A fast analysis of those scenarios highlights that they are related to two types of installations: pipes (for scenarios 6, 7 and 9) and loading/unloading activities (scenarios 11 and 22).

Given the location of those scenarios in the acceptability matrix, we are more interested in reducing consequences intensity than probability. The following options are suggested:

- Reduce pipes diameters lowering the quantities of dangerous products emitted in case of loss of containment.

- Put in place detection devices coupled with upstream valves.

- Study the possibility of moving away the loading and unloading activities to other areas of the plant.

Step 3: Vulnerability reduction

In the lack of scenarios classified in the red zone, there is no need to process this step.

Step 4: The global scenario

Steps 1 and 2 allowed us to identify the following options:

1. Improve emergency planning to reduce evacuation delays below $1 \mathrm{~h}$.

2. Reduce pipes diameters.

3. Put in place detection devices coupled with upstream valves.

4. Displace loading and unloading activities.

The global option is thus easy to establish through a combination of option 1 and at least one of the three other options of hazard reduction.

\section{Conclusions and perspectives}

The decision support procedure described here aims at offering a global framework to local stakeholders dealing with issues of transport infrastructure protection. It can be used both for protecting existing infrastructures and secure future ones by comparing different protection alternatives at the design stage.

If the procedure can be adapted to various regulatory contexts where likelihood and severity are estimated differently, it still requires a clear regulatory framework defining acceptability thresholds to be used.

Regarding policy issues, applying the suggested procedure may provide the decision makers with two important benefits. The first one is the ability to demonstrate in a public context a systematic and still context adapted approach. Room for stakeholders' participation is given with a real possibility to influence decision outcomes. Consequently, decisions acceptability is expected to be enhanced in potentially conflicting situations when it is particularly difficult to build.

The second benefit is the demonstration of fairness as far as the efforts expected from stakeholders to improve safety are concerned. As stated earlier, PPRT policy relies on conjoint efforts between various parties: inhabitants, economic activities, local authorities, hazardous plants owners... A lack of protection efforts 
dedicated to transportation infrastructures may be interpreted as a fairness violation regarding the efforts expected from other societal stakeholders.

A last and still important point is the need for decision support approaches in participative contexts that maintain a subtle balance between complexity and sophistication on the one hand and transparency and inclusiveness on the other hand. The various discussions we had with stakeholders regarding the case of infrastructures protection presented here confirm the vital necessity of this balance.

\section{References}

Aven, T. (2013). How to define and interpret probability in a risk and safety settings. Safety science, 51, 223, 231.

Basta, C., Neuvel, J.M.M., Zlatanova, S., Ale, B. (2007). Risk-maps informing land use planning processes. A survey of the Netherlands and United Kingdom recent developments. Journal of hazardous materials 145, 241-249.

Christou, M., Gyenes, S., Struckl, M. (2011). Risk assessment in support to land use planning in Europe: Towards more consistent decisions? Journal of Loss prevention in process industry 24(3), 219-226.

Diestel, R. (2006). Graph theory. Springer-Verlag editions, Germany.

Duijm, N.J. (2009). Acceptance criteria in Denmark and EU. Report to the Danish Ministry of Environment. Available to download at http://www2.mst.dk/udgiv/publications/2009/978-87-7052-920-4/pdf/978-87-7052921-1.pdf (Accessed October 2013).

Grooijer, L., Cornil, C., Lenoble, C. (2010). International benchmark study of a fictitious LPG Plant. A comparison of the QRA approach of HSE (UK), RIVM (NL), INERIS (FR) and FPMs (Wallon region of Belgium). Proceedings of the $13^{\text {th }}$ international symposium of Loss prevention and safety promotion in the process industries. Brugge, Belgium.

HSE (2001). Reducing risks, protecting people. HSE's decision-Making Process. UK.

INERIS, CETE NC (2012), Cahier technique. Solutions de réduction de la vulnérabilité des usages des voies de transport, voies de transport et voies ferrées. Working document.

IRSN, 2012. Baromètre IRSN. La perception des risques et de la sécurité par les français (Safety and risk perception by French : the IRSN barometer). Paris, France.

Lakshmanan, T.R. (2011). The broader economic consequences of transport infrastructure investments. Journal of transport geography 19(1), 1-12.

Lenoble, C., Antoine, F., Bolvin, C., Kooi, E.S., Ujit de Haag, P.A.M. (2010). Benchmark study of a flammable liquid depot - A comparison of two risk analyses. ESREL proceedings, RODOS, Greece.

Lenoble, C., Durand, C. (2011). Introduction of frequency in France following the AZF accident. Journal of Loss prevention in process industry 24(3), 227-236.

Mazri, C., Chantelauve, G., Chevalier, M. (2010). Guide des pratiques d'association et de concertation dans le cadre des PPRT. Available to download at http://www.developpementdurable.gouv.fr/IMG/pdf/Guide_pratiques_association_concertation_PPRT.pdf (Accessed October 2013).

MEDDE (2006). Les Plans de prévention des Risques technologiques. Guide méthodologique. French minstry of environment. Available to download at http://www.developpement-durable.gouv.fr/Maitrise-de-1urbanisation-PPRT,12775.html (Accessed October 2013).

Okrent, D. (1998). Risk perception and risk management: On knowledge, resource allocation and equity. Reliability engineering and system safety 59(1), 17-25.

Ostanello, A., Tsoukias, A. (1993). An explicative model of public inter organizational interactions. European Journal of Operational Research 70, 67-82. 
Prati, G., Zani, B. (2012). The effect of the Fukushima nuclear accident on risk perception, antinuclear behavioral intentions, attitude, trust, environmental beliefs and values. Environment and behavior, 44(3), 117.

Renn, O. (1998). Three decades of risk research: accomplishments and new challenges. Journal of risk research $1,49-71$.

Rosenhead, J., Mingers, J. (2004). A new paradigm of analysis In Rosenhead, J. and Mingers, J. (Eds), Rational analysis for a problematic world revisited (pp 1-21). Wiley and Sons, UK

Short, J.F. (1984). The social fabric of risk: towards the social transformation of risk analysis. American Sociological review 49, 711-725.

Taveau, J. (2010). Risk assessment and land-use planning regulations in France following the AZF disaster. Journal of Loss Prevention in the Process Industries, 23( 6), 813-823.

Webler, T., Renn, O. (1995). A brief primer on participation: Philosophy and practice. In Renn. O., Webler, T. and Wiedemann, P. (Eds), Fairness and Competence in Citizen Participation: Evaluating Models for Environmental Discourse (pp. 17-33) Kluwer Academic Publishers Dordrecht. 